\title{
Investigation of the participatory approach to Decision making for Urban Regeneration Intervention
}

\author{
Sumana Jayaprakash, Asst Professor, Department of Civil Engineering, Malnad College of Engineering, \\ Hassan. Email id: si@mcehassan.ac.in \\ Dr. Vimala Swamy, Professor, School of Architecture, REVA University, Bengaluru, Email Id: \\ vimalaswamy@reva.edu.in
}

Abstract:

Public participation in the decision-making process in Urban Interventions is the key to the success of the project for improving the quality of life of its citizens. The citizen has the democratic right to express his needs and aspiration; he is the final user who experiences the outcomes of the policy decisions. Non involvement of the citizens in the planning process can bring about the misinterpretation of the intention of political leadership and lead to opposition and protest. The inadequate understanding of citizens of the urban context makes public participation ineffective. In this context, the decision-makers are often faced with the challenges of the level of confidence of the citizens about their ideas and responses being incorporated in the project and the confidence of the citizens in the local urban authority in its ability to carry out the project. However, the decision-makers base their decision on the assumption that the citizens have a general understanding of the urban issues. This research work investigates the basis of this assumption. 1. Do the citizens have confidence that the local urban authority considers their choices and responses in the course of decision making 2. Do the citizens have the confidence that the local urban authority can undertake the Urban Regeneration project 3 . Whether in the decision-making process of urban regeneration intervention, citizen's responses are backed by a general understanding of urban issues. The case study taken up is of Hassan city. Five areas of crucial importance have been selected based on the development plan report of the city. The integrated approach aims to find the most appropriate area for proposing the Urban Regeneration project. The framework adopted includes 1. Questionnaire survey: to collect citizens' responses 2. Analysis of variance (ANNOVA) for analysis of the data collected.

Keywords: Investigation, citizens, urban context.

\section{Introduction:}

The main goal of the regeneration project is to cater to the economic, social, and environmental factors of an urban area undergoing decay by unregulated development and underutilized and unused areas. In the wake of economic development, there is a need to identify the competing alternatives and prioritize the most appropriate intervention. (Della Spina, 2019). the evaluation of alternative scenarios is a complex decision problem where different aspects need to be considered simultaneously, taking into account both technical parameters, which are based on experiences as well as feeling like the level of confidence, etc. (Berta et al., 2018) An Urban intervention involves the integrated collective negotiated effort of public, private and community 
sectors in finding appropriate solutions to the changing circumstances in the economic, environmental, social and political context. (City Investments To Innovate, Integrate \& Sustain (CITIIS) 2018)) This in turn is likely to bring about changes in the Institutional structures. Development of the Institutional structure is a means for determining policies and actions for the preparation of specific proposals and is characterized by the development of the framework within which plans and projects are designed and implemented. (URDPFI Guidelines : Ministry of Urban Development n.d.) Within this framework, the intended outcomes, the sense of purpose and co-operation, roles and responsibilities of the key players and organizations are worked out. (Roberts, 2000) It is based on a detailed analysis of the condition of the area and addresses the physical, social, economic, and environmental conditions. The integrated strategy and implementation are developed in accord with the aims of sustainable development by making it possible to manage human activities for the best use of the existing features on-site and setting clear quantifiable objectives for the prosperity of the urban environment. Participation and cooperation of all stakeholders are to be achieved through partnerships and other modes. The participation of citizens in the planning process is important as it makes it possible for the public to express their democratic right to be involved in the city planning process. It allows the community to express their needs and aspirations that can otherwise manifest as protest and opposition. (Swamy. 2020 ) (Rana Amirtahmasebi, Mariana Orloff, Sameh Wahba, n.d.)

This research paper is divided into four parts. The first part explains the methodology adopted. The second part deals with the data collection method. The third part is the analysis of the data and the fourth part is on discussions and conclusions.

\section{Methodology:}

The research Philosophy adopted is interpretivism which emphasizes that the individual is influenced by social, cultural, and environmental factors. (A new strategy of sustainable neighbourhood planning: Five Principles 2015) (O'Sullivan 2020) Hence the focus is on the holistic understanding of the participants and their responses. The Inductive research approach has been adopted with emphasis on qualitative data. (Kothari. C. R, 2004) Action research strategy has been used where the researcher implements his idea with a practical approach with the involvement of the citizen participants. Employing the Cross-sectional time horizon, data has been collected at one point in time. For the data collection method, responses to the questionnaire have been collected by convenience sampling. Two-way ANOVA has been used for data analysis. This research work examinedthe following aspects. 1. Do the citizens have confidence that the local Urban authority takes their choices and responses into consideration 2. Do the citizens have the confidence that the local urban authority will be able to undertake the Urban Regeneration project. 3. Whether in the decision-making process of Urban regeneration intervention, citizens have adequate understanding and can contribute positively by their experience of living in the city. Are their choices different from the citizens who have undergone a course on 'urban design and regeneration.' The case study taken up is of Hassan city. Five areas of crucial importance have been selected based on the development plan report of the city. 
The integrated approach aims to find the most appropriate area for proposing the Urban Regeneration project. The framework adopted includes the 1. Questionnaire survey: to collect citizen's responses and 2. Two-way ANOVA with replication for analysis of the data collected.

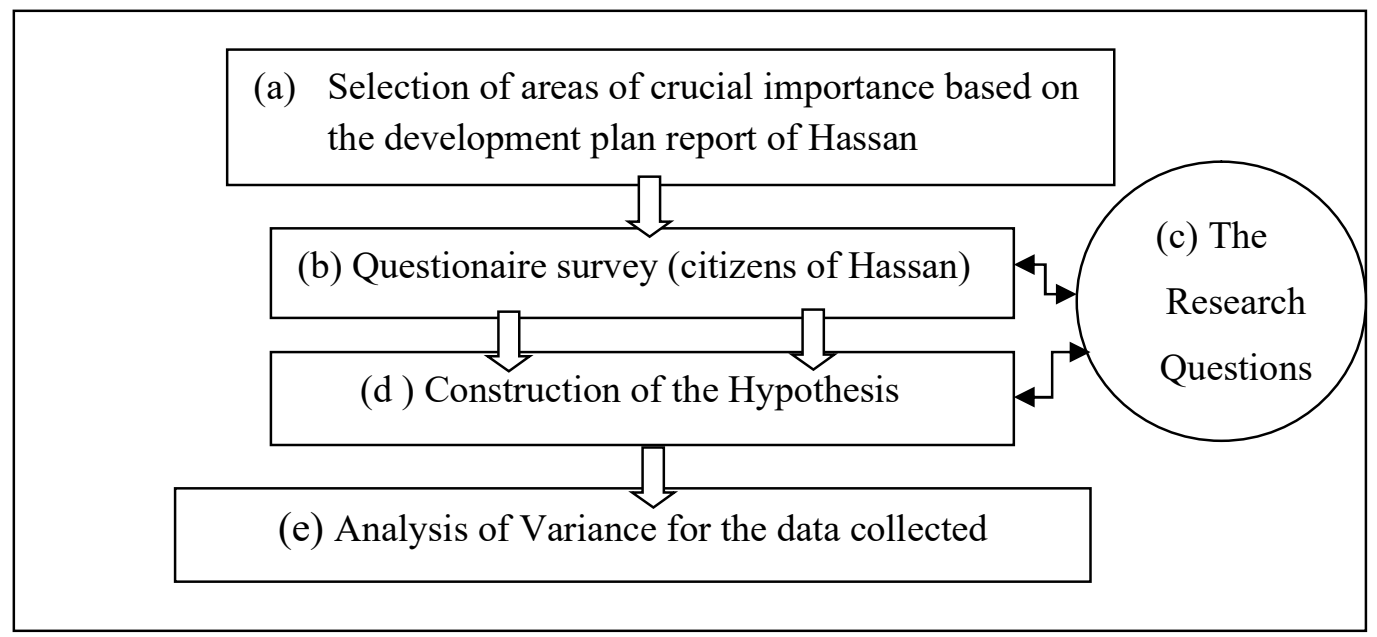

Chart1: Methodology (Source : Author research approach)

\section{2(a) Selection of areas of crucial importance based on the development plan report of Hassan}

Five areas were selected for possible Urban Regeneration Intervention based on the Urban problems stated in the Development Plan Report of Hassan. They were as follows:

1. Protection and development of Hunasikere Water body as a sensitive zone

2. Infrastructure Development of wholesale market, shandy area, Truck handling zones at Santhepete.

3. Development of slums and low-income housing.

4. Development of parks and playgrounds.

5. Restoration of the historic Devigere tank and Kattinakere Retail market development.

To define the areas specifically, Slums and low-income housing area has been identified as pension mohalla. Parks have been defined as Maharaja Park and playgrounds have not been considered. The restoration of the historic Devigere tank and the Kattinakere retail market development was combined due to their proximity and scale factor. The questionnaire asked the respondents for their first preference for each parameter in terms of appropriate area choice. The parameters as stated below had been adequately explained to present it clearly to the respondent.

\section{2(b) Questionaire survey (citizens of Hassan)}

Questionaire survey was carried out to 100 students between the age group of 20-30 by adopting the convenience sampling method. 50 students were from the class of open elective course on "Urban Design and Regeneration" belonging to $6^{\text {th }}$-semester engineering across 
departments (Student Group 1). 50 students were randomly selected from engineering and other disciplines who had not undergone the open elective course (Student Group 2). A total of eight factors were taken up in the framing of the questionnaire. Convenience sampling was undertaken. Google forms were used for collecting responses. The responses taken up for each set of parameters from fifty students (Student Group 1) were compared with the responses taken from the same number of students of the same age group (Student Group 2). All students who participated in responding to the questionnaire were familiar with the city of Hassan. The Research question was "Do the citizens of the city have a general understanding of the city context? This was examined by analyzing the choices of the two groups.

The citizens were to select their preference out of the five probable areas as to best fit the parameters explained in the question. Total numbers of questions to answer were ten. The parameters and the variables in the questions framed, were based on literature study carried out by the researcher and were as follows:

\begin{tabular}{|c|c|c|}
\hline $\begin{array}{l}\text { Sl. } \\
\text { No }\end{array}$ & Parameters & Variables detailed out in the question \\
\hline \multirow[t]{5}{*}{1} & City’s identity/ Image & city's unique cultural identity \\
\hline & & Visibility and Accessibility \\
\hline & & Places of historic importance \\
\hline & & appropriate use and interlinkage for the site \\
\hline & & Efficient connectivity and linkages \\
\hline \multirow[t]{5}{*}{2} & Social and Institutional facilities & public space and linkages \\
\hline & & Building/area boundaries as public statements \\
\hline & & Interpendent functions in the area \\
\hline & & Privately owned public spaces \\
\hline & & Unorganized activities \\
\hline \multirow[t]{3}{*}{3} & Transportation network & pedestrian-friendly places \\
\hline & & Cycle tracks and walking tracks \\
\hline & & Innovative transport services \\
\hline \multirow[t]{4}{*}{4} & Inclusive Planning & Includion of elderly and children \\
\hline & & Consideration of gender \\
\hline & & Participatory process of planning \\
\hline & & Implementation strategies \\
\hline \multirow[t]{4}{*}{5} & Environmental factors & city-level environmental concerns \\
\hline & & Environmental consideration in interlinking spaces \\
\hline & & Eco-friendly construction \\
\hline & & Waste management, rainwater harvesting \\
\hline \multirow[t]{6}{*}{6} & Physical Factors & Building form and massing \\
\hline & & Urban Design Guidelines \\
\hline & & Building bylaws \\
\hline & & Infrastructure planning \\
\hline & & Implementation strategies \\
\hline & & Monitoring and maintenance \\
\hline \multirow[t]{5}{*}{7} & Administrative mechanisms & policy guidelines \\
\hline & & administration hierarchy \\
\hline & & sharing resources policy \\
\hline & & Administration responsibilities \\
\hline & & Environmental policy guidelines \\
\hline 8 & Financial \& resource mobilization & Self-financing strategies \\
\hline
\end{tabular}




\begin{tabular}{|l|l|l|}
\hline & & Public-Private partnerships \\
\hline & & Implementation strategies \\
\hline & & monitoring, and documentation \\
\hline
\end{tabular}

Table 1: The List of parameters and the variables used in the questionnaire (Source: Literature survey by researcher)

Two additional questions were asked to ascertain the confidence level of the citizens in the Hassan planning authority in implementing the urban regeneration project and the level of belief that citizen's had of their suggestions being incorporated in the project. Understanding the citizen's feelings and the level of confidence possessed in the Local Urban Authority was important as it determined the interest and involvement to respond to the questionnaire.

Following were the questions framed:

Question 1:

Restore the city's identity as a historic core with mixed-land use, Preserve and revitalize to reflect the city's unique cultural identity Identification and documentation of places of historic importance. Visibility and Accessibility to people. Defining appropriate use and interlinkage for the site and the surrounding. Efficient connectivity and linkages with the city.

Question 2:

Social and Institutional facilities, parks, and open spaces integrated. City Level public space and linkages. Interconnectivity of spaces and functions with access to the surroundings Building/area boundaries as public statements Provision of Interpendent functions in the area and definition in terms of space. Privately owned public spaces. Unorganized activities spaces and design parameters.

Question 3:

Transportation network pedestrian-friendly places and network. Cycle tracks and walking tracks connecting the various activities Innovative transport services like electric trams, rent a cycle, scooter, etc.

Question 4:

Inclusive Planning to accommodate the interests of all people. Design parameters to include the elderly and children Requirements of people of all age groups and gender considered and included the Participatory process of planning and implementation. Feedback mechanism for reworking on plan and implementation strategies.

Question 5:

Environmental factors. Identification of city-level Factors of environmental concern and incorporation Integration of factors of the environment into the interlinking spaces and structures Building level integration of Eco-friendly construction Innovative approaches to Waste management, rainwater harvesting, and such other factors.

Question 6:

Physical Factors. Building form and massing Interlinkages between the buildings and movement Guidelines for public and Institutional buildings and open spaces in alignment with the Urban Design Guidelines Individual Private Building bylaws concerning the urban design guidelines common Street interface design Rooftop guidelines Infrastructure planning (water supply, 
sewerage, electricity) and implementation Building guidelines policies, Implementation strategies, maintenance and improvement, and reworking, monitoring, and documentation Infrastructure implementation.

Question 7:

Administrative mechanisms. Historic precinct and structures policy guidelines for users, administration hierarchy, responsibilities Use policy, sharing resources policy, time use policy and public policy Transportation policy guidelines, Parking policies, Implementation and monitoring Environmental policy guidelines Building guidelines policies,

Question 8:

Financial and other resource mobilization instruments. Financial resource mobilization Selffinancing strategies, Public-Private partnerships for financial sustainability Implementation strategies, maintenance, and improvement, and reworking, monitoring, and documentation Infrastructure implementation.

Question 9:

According to you the Hassan Local Authorities will be able to successfully carry out the Regeneration Project.

Question 10:

Your level of belief that Citizen's ideas are incorporated in the project.

\section{(c) The Research Questions:}

For the selection of the most appropriate area for the Urban Regeneration Project on eight parameters by two groups of students. Outcome (Result) is the effectiveness of the eight parameters on the two groups of citizens in determining the most appropriate area for the Urban Regeneration project. The two factors affecting the result are 1. The eight parameters. 2. The responses of the two groups of students. The significance level taken is 0.05 . The questions are 1 . Are the eight parameters significantly different? 2. Are the responses of the two groups significantly different? 3 . Is the interaction term significant?

\section{(d) Construction of the Hypothesis:}

Null Hypothesis $\mathrm{H}^{0}$ : "There is no significant difference in the responses for the most appropriate area selection for Urban Regeneration project for the eight parameters by the two groups of students"

Alternative Hypothesis $\mathrm{H} 1^{\mathrm{A}}$ : "There is a significant difference in the responses for the most appropriate area selection for Urban Regeneration project for the eight parameters by the two groups of citizens"

Null Hypothesis $\mathrm{H} 2^{0}$ : "There is no effect of the eight parameters in the appropriate selection of area for Urban Regeneration project"

Alternative Hypothesis $\mathrm{H}_{2}^{\mathrm{A}}$ : "There is a significant effect of the eight parameters in the appropriate selection of area for Urban Regeneration project" 


\section{(e ) Analysis of Variance for the data collected}

The responses collected from Group 1 and Group 2 to question No.9 and 10 were analysed.

The following table presents the responses and analysis of the question Citizens' responses to the question 9: "According to you the Hassan Local Authorities will be able to successfully carry out the Regeneration Project."

\begin{tabular}{|c|c|c|c|c|c|c|c|c|}
\hline Data Collected & \multicolumn{2}{|c|}{$100 \%$} & $80 \%$ & $60 \%$ & $40 \%$ & $20 \%$ & $0 \%$ & \\
\hline Group 1(\%) & \multicolumn{2}{|c|}{2} & 34 & 40 & 20 & 4 & 0 & \\
\hline Group $2(\%)$ & \multicolumn{2}{|c|}{10} & 40 & 30 & 12 & 8 & 0 & \\
\hline \multicolumn{2}{|c|}{ Anova: Single Factor } & \multicolumn{2}{|c|}{ SUMMARY } & & & & & \\
\hline \multicolumn{2}{|c|}{ Groups } & \multicolumn{2}{|c|}{ Count } & Sum & Average & Variance & & \\
\hline \multicolumn{2}{|l|}{ Row 1} & \multicolumn{2}{|c|}{5} & 100 & 20 & 294 & & \\
\hline Row 2 & & \multicolumn{2}{|c|}{5} & 100 & 20 & 202 & & \\
\hline \multicolumn{2}{|l|}{ ANOVA } & & & & & & & \\
\hline \multicolumn{2}{|c|}{ Source of Variation } & \multicolumn{2}{|c|}{$S S$} & $d f$ & $M S$ & $F$ & $P$-value & $F$ crit \\
\hline \multicolumn{2}{|c|}{ Between Groups } & \multicolumn{2}{|c|}{0} & 1 & 0 & 0 & 1 & 5.317655 \\
\hline \multicolumn{2}{|c|}{ Within Groups } & \multicolumn{2}{|c|}{1984} & 8 & 248 & & & \\
\hline \multicolumn{2}{|l|}{ Total } & \multicolumn{2}{|c|}{1984} & 9 & & & & \\
\hline
\end{tabular}

Table 2: Citizens' responses to the question10: "According to you the Hassan Local Authorities will be able to successfully carry out the Regeneration Project." Source: Questionaire survey by researcher and analysis

The following table presents the responses and analysis of the question Citizens' responses to the question 10: "Your level of belief that Citizen's ideas are incorporated in the project"

\begin{tabular}{|c|c|c|c|c|c|c|c|c|}
\hline Data Collected & \multicolumn{2}{|c|}{$100 \%$} & $80 \%$ & $60 \%$ & $40 \%$ & $20 \%$ & $0 \%$ & \\
\hline Group 1(\%) & \multicolumn{2}{|c|}{2} & 24 & 42 & 24 & 6 & 2 & \\
\hline Group 2(\%) & \multicolumn{2}{|c|}{13} & 27 & 35 & 17 & 2 & 6 & \\
\hline \multicolumn{2}{|c|}{ Anova: Single Factor } & \multicolumn{2}{|c|}{ SUMMARY } & & & & & \\
\hline \multicolumn{2}{|l|}{ Groups } & \multicolumn{2}{|c|}{ Count } & Sum & Average & Variance & & \\
\hline \multicolumn{2}{|l|}{ Row 1} & \multicolumn{2}{|c|}{6} & 100 & 16.66667 & 258.6667 & & \\
\hline \multicolumn{2}{|l|}{$\frac{\text { Row } 2}{\text { ANOVA }}$} & \multicolumn{2}{|c|}{6} & 100 & 16.66667 & 157.0667 & & \\
\hline \multicolumn{9}{|l|}{ ANOVA } \\
\hline \multicolumn{2}{|c|}{ Source of Variation } & \multicolumn{2}{|c|}{$S S$} & $d f$ & $M S$ & $F$ & P-value & $F$ crit \\
\hline \multicolumn{2}{|c|}{ Between Groups } & \multicolumn{2}{|c|}{0} & 1 & 0 & 0 & 1 & 4.964603 \\
\hline \multicolumn{2}{|c|}{ Within Groups } & \multicolumn{2}{|c|}{2078.667} & 10 & 207.8667 & & & \\
\hline \multicolumn{2}{|c|}{ Total } & \multicolumn{2}{|c|}{2078.667} & 11 & & & & \\
\hline
\end{tabular}

Table 3: Citizens responses to the question: "Your level of belief that Citizen's ideas are incorporated in the project" Source: Questionaire survey by researcher and analysis

One-Way ANOVA ("analysis of variance") compares the means of two or more independent groups in order to determine whether there is statistical evidence that the associated population means are significantly different. The $\mathrm{P}$ value of 1 in the above two tables clearly suggests no difference between the groups other than chance.

The data set was analyzed by Two way ANOVA with replication for the responses collected from Group 1 and Group 2 and the following output was obtained.

\begin{tabular}{|l|l|l|l|l|l|l|l|l|l|}
\hline \multicolumn{2}{|l|}{ Anova: Two-Factor With Replication } \\
\hline SUMMARY & Identity & Institu & Linkag & Social & Environ & Physi & Admini & Finan & Total \\
\hline
\end{tabular}




\begin{tabular}{|c|c|c|c|c|c|c|c|c|c|}
\hline & & tions & es & & mental & cal & strative & cial & \\
\hline \multicolumn{10}{|l|}{ Group 1} \\
\hline Count & 50 & 50 & 50 & 50 & 50 & 50 & 50 & 50 & 400 \\
\hline Sum & 116 & 138 & 143 & 149 & 116 & 123 & 143 & 137 & 105 \\
\hline Average & 2.32 & 2.76 & 2.86 & 2.98 & 2.32 & 2.46 & 2.86 & 2.74 & 2.66 \\
\hline Variance & 1.08 & 1.41 & 1.14 & 1.49 & 1.85 & 1.60 & 1.76 & 1.46 & 1.51 \\
\hline \multicolumn{10}{|l|}{ Group 2} \\
\hline Count & 50 & 50 & 50 & 50 & 50 & 50 & 50 & 50 & 400 \\
\hline Sum & 118 & 150 & 143 & 182 & 106 & 142 & 119 & 140 & 1100 \\
\hline Average & 2.36 & 3 & 2.86 & 3.64 & 2.12 & 2.84 & 2.38 & 2.8 & 2.75 \\
\hline Variance & 2.36 & 1.18 & 2.33 & 1.42 & 1.99 & 1.69 & 2.00 & 1.76 & 2.00 \\
\hline Count & 100 & 100 & 100 & 100 & 100 & 100 & 100 & 100 & \\
\hline Sum & 234 & 288 & 286 & 331 & 222 & 265 & 262 & 277 & \\
\hline Average & 2.34 & 2.88 & 2.86 & 3.31 & 2.22 & 2.65 & 2.62 & 2.77 & \\
\hline Variance & 1.70 & 1.30 & 1.72 & 1.55 & 1.91 & 1.66 & 1.91 & 1.59 & \\
\hline \multicolumn{10}{|l|}{ ANOVA } \\
\hline $\begin{array}{l}\text { Source of } \\
\text { Variation }\end{array}$ & SS & $\mathrm{df}$ & MS & F & $\mathrm{P}$-value & F crit & & & \\
\hline Sample & 1.5312 & 1 & 1.5312 & 0.9243 & 0.3366 & 3.8533 & & & \\
\hline Columns & 80.359 & 7 & 11.48 & 6.9297 & $5 \mathrm{E}-08$ & 2.0212 & & & \\
\hline Interaction & 21.299 & 7 & 3.0427 & 1.8367 & 0.0773 & 2.0212 & & & \\
\hline Within & 1298.8 & 784 & 1.6566 & & & & & & \\
\hline Total & 1402 & 799 & & & & & & & \\
\hline
\end{tabular}

Table Anova: Two-Factor With Replication using Excel Data Analysis

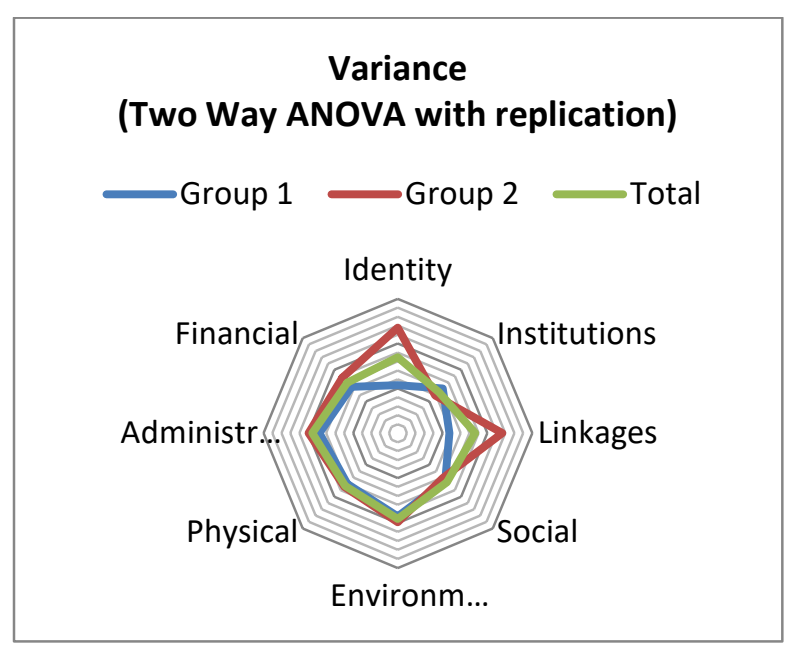

Fig 3: Variance (Group1, Group 2 and total)

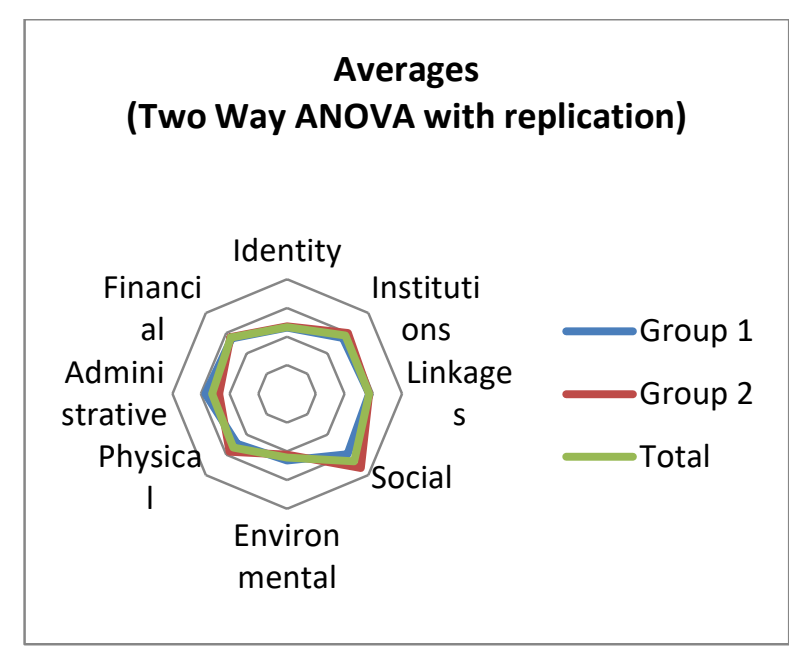

Fig 4: Averages (Group1, Group 2 and total)

There is noticeable variance only in the two parameters of Identity and Linkages between the two groups. There is no significant difference in the averages of the samples, the parameter, and the total.

\section{Discussions and Conclusions:}


3.1 The p-value for the sample (groups of students) is 0.3366 and is higher than 0.05 . It is not significant in the response to the parameters. Hence the null hypothesis is accepted. Null Hypothesis: "There is no difference in the responses for the eight parameters by the two groups of citizens" for the most appropriate area selection for the Urban Regeneration project.

3.2 The p-value for the columns (the parameters) $5 \mathrm{E}-08$ is very less than 0.05 . It is significant for the appropriate selection of the area. Hence the null hypothesis $\mathrm{H} 2^{0}$ is rejected. The alternative hypothesis $\mathrm{H}^{\mathrm{A}}$ is accepted. Alternative Hypothesis 2: "There is a significant effect of the eight parameters in the appropriate selection of area for Urban Regeneration project"

3.3 The p-value of the interaction 0.0773 is higher than 0.05 . Hence it is not significant

The selection of the most appropriate area for the Urban Regeneration project is not dependent on the group of students. The responses of the two groups are not significantly different. It proves the fact that students have a general understanding of Urban issues and their responses are not significantly different from the students who have undergone a course on Urban Design and Regeneration. The decision-maker's assumption that citizens have a general understanding of Urban issues is verified and is proved to be correct.

There is a significant effect of the eight parameters in the appropriate site selection. The appropriate selection of area for the Urban Regeneration project is dependent on the eight parameters, but not dependent on the groups of students. The appropriate selection was irrespective of the group of students. Hence the assumption that citizens have a general understanding of the urban issues is proved to be correct.

4. Limitations of the work: The work has been carried out by considering only students of age group 20-30 years, which is not truly representative of the population. Further studies on similar lines can be carried out considering all age groups and people from all walks of life with various occupations and income groups. This work has been carried out based on convenience sampling. Systematic sampling of cluster sampling can be adopted and further work can be carried out.

\section{Bibliography:}

1."A new strategy of sustainable neighbourhood planning: Five Principles." UN-HABITAT. https://unhabitat.org/a-new-strategy-of-sustainable-neighbourhood-planning-five-principles. 2015.

2. Berta, M., Bottero, M., \& Ferretti, V. (2018). A mixed-methods approach for the integration of urban design and economic evaluation: Industrial heritage and urban regeneration in China. Environment and Planning B: Urban Analytics and City Science, 45(2), 208-232. https://doi.org/10.1177/0265813516669139

3.Della Spina, L. (2019). A multi-level integrated approach to designing complex urban scenarios in support of strategic planning and urban regeneration. Smart Innovation, Systems, and Technologies, 100(September 2018), 226-237. https://doi.org/10.1007/978-3-319-92099-3_27 
4. Enabling Inclusive Cities: Tool Kit for Inclusive Urban Development. Asian Development Bank. https://dx.doi.org/10.22617/TIM157428. 2016

5. G. Munda, P. Nijkamp, P. Rietveld,. 1994. "Qualitative multicriteria evaluation for environmental management,." Ecological Economics, Volume 10, ( Issue 2,): 97-112,.

6. Kothari. C. R. (2004). Research Methodology: Methods and Techniques. New Age International

(P) Limited, Publishers 4835/24, Ansari Road, Daryaganj, New Delhi - 110002.

7. Nassar, U. A. E. (2021). Urban Acupuncture in Large Cities: Filtering Framework to Select Sensitive Urban Spots in Riyadh for Effective Urban Renewal. Journal of Contemporary Urban Affairs, 5(1), 1-18. https://doi.org/10.25034/ijcua.2021.v5n1-1

8. National Institute of Urban Affairs. citiis.niua.org, www.niua.org. 2018.

9. n.d. http://mohua.gov.in/link/urdpfi-guidelines.php.

10. O'Sullivan, S., O'Connell, C., \& Byrne, L. 2020. "Children and Young People's Perspectives on Urban Regeneration. ." Social Inclusion, 8(3), 77-87. doi:http://dx.doi.org/10.17645/si.v8i3.2884.

11. Rana Amirtahmasebi, Mariana Orloff, Sameh Wahba, A. A. (n.d.). Regenerating Urban Land: Practitioner's guide to leveraging Private Investments. World Bank Group. https://www.worldbank.org/en/topic/urbandevelopment/publication/regenerating-urban-land-apractitioners-guide-to-leveraging-private-investment

12. Roberts, P. (2000). The evolution, definition, and purpose of urban regeneration. Urban Regeneration, 9-36.

12. Shenvi, ApoorvaSlangen, Ron H. 2018. Enabling Smart Urban Redevelopment in India through Floor Area Ratio Incentives. South Asia Working Papers, Asian Development Bank. https://dx.doi.org/10.22617/WPS189452-2.

13. Swamy., Dr. Vimala. 2020 . Smart Keys for smart eco-friendly cities. Bengaluru: BUUKS.,. https://www.amazon.in/Smart-Keys-Eco-friendly-Cities/dp/9390507642. 